\title{
Islamic Finance - from Submission to Global Sustainability
}

\author{
Nik Mohd Hasyudeen Yusoff
}

The practice of Islamic finance emerged over 1,400 years ago but the resurgence started in the 1970s. To some, Islamic finance is just one of the options to consider in their fund raising exercise. However, if we look at the bigger picture, this faith-based financing system functions beyond merely providing Muslims with interest-free banking services. For Muslims, Islamic finance is a part of the larger scheme of submission to the Creator. Therefore, Islamic finance is not only about getting the concepts, structures and processes of the financing schemes right, but the outcomes should be in line with the Islamic teachings and values.

In addition to avoiding the charging of interest, business transactions in Islam should also be free of terms and conditions that are vague and uncertain, do not involve elements of gambling, and are not based on assets with no value or businesses that are prohibited by Islam, such as liquor, tobacco and gambling. Consequently, Islamic finance promotes business activities that generate profit from transactions supported by genuine valuable assets in a legitimate and fair manner from the Islamic perspective, as prescribed by Shariah or Islamic law.

Applying this approach, investors and funders should also be given the comfort that not only do the businesses and assets to be funded comply with Shariah requirements but that the outcome of the business or asset utilisation benefits society at large. For example, property development per se is an acceptable business activity but if a project results in severe destruction to the environment and renders the squatters on the land under development homeless, then the party providing the funding should exercise caution in proceeding with the transaction. Furthermore, in an era where the global community is cautious about its carbon footprint, it would not be a surprise if this issue is given more emphasis in evaluating and structuring Islamic financial transactions.

Another important element of Islamic finance is that profit is shared based on the risk sharing arrangements between the parties involved in the transactions. The ranges of products offered by Islamic financial institutions are based on how risks are shared by the contracting parties. By recognising such exposure to risks, Islamic finance encourages strong risk management culture and practices to be embraced by the promoters, investors and other parties in ensuring that their interests are not compromised. The parties would not be remunerated to the extent of the productivity of the financial capital provider and the entrepreneurial effort, which results in profit.

During the global financial crisis, we observed the demise and failure of established institutions and corporations, which adopted advanced risk 
management frameworks. Among the lessons learned was that risk management was adopted more on the "ticking the box" basis instead of being applied holistically by these organisations. There is also pressure for Islamic finance products to mimic their conventional cousins for easier acceptance in new markets. The challenge for Islamic finance moving forward is how far the values on which the whole concept stand are internalised and applied by the parties involved in this method of financing.

There is also a risk that instead of preserving the principles behind Islamic finance, transactions are structured based on standard checklists that could compromise the outcome intended by Islam. This, if not carefully applied, could taint the structure, especially when non-compliance with Shariah principles is considered part of the risks for Islamic banks and other financial institutions.

One of the consequences of the need for strict adherence to Islamic principles is that the investment opportunities would come from a smaller pool. At the same time, due to its stage of development in most jurisdictions, Islamic finance has fewer risk management and mitigation tools, as some conventional means, such as derivatives, may not fulfil the requirements of Shariah. This will be mitigated as the financial system develops further with more products made available in the market.

As Islamic finance gains more popularity and attracts interest from those beyond the Muslim community, such as global financial institutions and corporations, the issue of how Islamic finance transactions are reported in the financial statements of those investors and issuers becomes increasingly important. Furthermore, convergence with the International Financial Reporting Standards (IFRS) in various jurisdictions makes it more difficult for standalone practices to remain viable.

One of the champions in this issue is the Accounting and Auditing Organisation for Islamic Financial Institutions or AAOIFI. It has issued a number of accounting standards to be used when reporting transactions that comply with the principles of Shariah. However, questions are now being asked concerning whether IFRS can be used for such purposes. There are now initiatives in exploring the applicability of IFRS on Islamic finance transactions and to identify possible issues that can arise therefrom. It is also argued that the way Islamic finance transactions are accounted for under IFRS does not nullify the validity of the transactions from the Shariah perspective.

As Islamic finance normally involves the financial services industry, it requires a supportive legal framework to function effectively. Development in this area has been observed in many parts of the world including the Middle East, Europe and Asia to name a few. The Islamic Financial Services Board (IFSB) has been established as a standard setting institution to ensure best practices and help member countries with regulating Islamic financial institutions. Malaysia, for instance, has enacted various laws to support the growth and development of Islamic-related financial services including banking, takaful, wealth management, 
mutual funds and other services, which provide a comprehensive offering to the consumers and other participants.

As in other industries, talent and expertise are key to the growth of Islamic finance and could be one of the roadblocks for further progress. The demand for expertise is not only in the area of Shariah related knowledge but includes other disciplines of knowledge that will provide institutions involved in Islamic finance with a comprehensive Islamic financial knowledge. Among the institutions that are specialising in this are the International Centre for Education in Islamic Finance (INCEIF) in Malaysia and the Markfield Institute of Higher Education in the United Kingdom.

The diversity of Shariah opinion is one of the issues perceived as creating some challenges in developing and promoting products in Islamic finance across the globe. So far, there has already been progressive development in the convergence of Shariah views and rulings and the mutual recognition of financial standards and products across jurisdictions despite differences of opinion among scholars concerning a few aspects of the application of Shariah. The Central Bank of Malaysia, for example, has embarked on the initiative to develop Shariah Parameters to promote a more consistent application of Islamic financial contracts. This is applied, particularly in determining the essential features of Islamic financial products derived from the underlying key Shariah principles.

Islamic finance should be viewed as a means to promote justice and to preserve the social order of society. From the risk-sharing concept to ensure that economic activities do not compromise the wellbeing of society, Islamic finance is and will continue to be attractive to the larger global community and not just confined to the Muslim society. There are challenges that need to be overcome to further refine the application of its concepts and practices. With the concerted effort by its global supporters, Islamic finance would continue to grow as a significant component of the global financial market.

\section{Notes}

Nik Mohd Hasyudeen Yusoff is the Chairman of the Malaysian Institute of Accountants' Financial Reporting Standards Implementation Committee for Islamic Finance. He is also a member of the Malaysian Accounting Standards Board (MASB), the Vice-President of the Asean Federation of Accountants (AFA), a member of the Executive Committee and Strategy Committee of the Confederation of Asian and Pacific Accountants as well as a member of CPA Australia's Public Practice Advisory Committee. 